\title{
Asymptomatic Human Paragonimiasis among the Karen People in Tak Province, Thailand: A Case Report
}

\author{
Teera Kusolsuk, ${ }^{1, *}$, Orawan Phuphisut', Wanna Maipanich', Somchit Pubampen'1, Surapol Sa-nguankiat', \\ Akkarin Poodeepiyasawat', Nirundorn Homsuwan', Srisuchart Mongkolmoo², Tippayarat Yoonuan', \\ Poom Adisakwattana', Udomsak Silachamroon ${ }^{3}$, Yukifumi Nawa ${ }^{4}$ \\ ${ }^{1}$ Department of Helminthology, Faculty of Tropical Medicine, Mahidol University, Thailand; ${ }^{2}$ Bangkok school of Tropical Medicine, Faculty of Tropical \\ Medicine, Mahidol University, Thailand; ${ }^{3}$ Department of Clinical Tropical Medicine, Faculty of Tropical Medicine, Mahidol University, Thailand; ${ }^{4}$ Tropical \\ Diseases Research Center, Faculty of Medicine, Khon Kaen University, Thailand
}

\begin{abstract}
During the mobile clinic activities in Tak Province, Thailand, Paragonimus sp. eggs were found in a fecal sample of a 72-year-old Karen resident. Paragonimus DNA was amplified from the stool sample and identified to $P$. heterotremus. The patient did not have any symptoms. Apparent pulmonary lesion was not found on the chest X-ray. The patient admitted habitual consumption of semi-cooked or roasted waterfall crabs for several years. The waterfall crabs collected from stream near the village were found negative for Paragonimus metacercariae. In northern Thailand, paragonimiasis remains as one of the public health concerns and should be ruled out for asymptomatic pulmonary patients.
\end{abstract}

Key words: Paragonimus heterotremus, paragonimiasis, asymptomatic

\section{INTRODUCTION}

Paragonimiasis is a disease caused by adult lung flukes (trematodes) of Paragonimus spp. that form nodular or cavitating lesions in the lungs or other viscera of host mammals. The infection in humans occurs via the consumption of fresh or brackish-water crustaceans or raw meat of paratenic host mammals contaminated with live metacercariae [1]. Among approximately 50 nominal species in the genus Paragonimus, only 2 species, $P$. heterotremus and $P$. westermani, have been identified as the human pathogens in Southeast Asia [2].

In Thailand, the first case of human paragonimiasis has been reported from Phetchabun Province [3]. Thereafter, certain endemic areas have been identified in the Saraburi [4] and Nakhon Nayok Provinces [5]. Moreover, sporadic cases have been reported in several places in Thailand, with relatively high incidence in the mountain regions of central, northern, and northeastern Thailand [6]. In northern Thailand, human paragonimiasis cases have been reported from Chiang Mai [7],

- Received 23 February 2019, revised 29 August 2019, accepted 16 September 2019.

*Corresponding author (teera.kus@mahidol.ac.th)

(c) 2020, Korean Society for Parasitology and Tropical Medicine

This is an Open Access article distributed under the terms of the Creative Commons Attribution Non-Commercial License (https://creativecommons.org/licenses/by-nc/4.0) which permits unrestricted non-commercial use, distribution, and reproduction in any

medium, provided the original work is properly cited.
Chiang Rai [8], Mae Hong Son [9], Phitsanulok [10,11], Lamphun [12], Kanchanaburi [13], and Nan [14] Provinces.

Tak Province is located in northern Thailand, and cases of paragonimiasis have occurred in several neighboring provinces, as listed as above. However, paragonimiasis cases have never been reported in Tak Province. During our mobile clinic services conducted in Tak Province, coproparasitological examination revealed the presence of Paragonimus sp. eggs in 1 of 343 stool specimens; this specimen was from a 72-year-old Karen female participant. To the best of our knowledge, this is the first case of human paragonimiasis recorded in Tak Province, and we describe the case details here.

\section{Parasitological findings}

Between December 2013 and February 2014, the Hospital for Tropical Diseases, Mahidol University, provided mobile medical services for villagers in Ban Maelah, Tha Song Yang District, Tak Province, northern Thailand, locating on the Thai-Myanmar border. The villagers comprised Thai and Karen individuals, and most of them were farmers working in the fields and forests. On each occasion, participants were from completely different communities.

We collected 343 fecal samples from villagers for coproparasitological examination using Kato's thick smear and simple thin smear techniques. The results are given in Supplementary 
Table S1. In brief, a half of the participants had parasitic infections. Hookworm infection was the most common helminthiasis, followed by ascariasis, trichuriasis, and minute intestinal fluke infections. Other helminthiases were rather rare. Protozoan parasites were less frequently detected than helminths, and they were mostly nonpathogenic species. Three pathogenic protozoans, Entamoeba spp, Giardia, and Blastocystis were detected at low incidence with low intensity. During this coproparasitological examination, Paragonimus sp. eggs with golden brown color, symmetric oval-shape and operculated one end (Fig. 1) were found unexpectedly in a fecal sample of an apparently healthy participant. The average size and ranges of 3 eggs were 86.7 (75.0-95.0) $\mu \mathrm{m}$ in length and 53.3 (50.0-57.5) $\mu \mathrm{m}$ in width.

\section{CASE DESCRIPTION}

Eggs of Paragonimus spp. were found with golden brown color, symmetric oval-shape and operculated one end (Fig. 1) in a fecal sample from a 72-year-old Karen female participant with no history of this infection. This patient did not exhibit any symptoms of pulmonary infection and appeared healthy. The patient denied suffering from any diseases but reported a smoking habit of hand-made cigarettes. Few years ago, the patient had developed chronic cough with sputum (not bloody) in the morning. The patient was screened for tuberculosis but was confirmed to be negative. Because minimal cough persist-

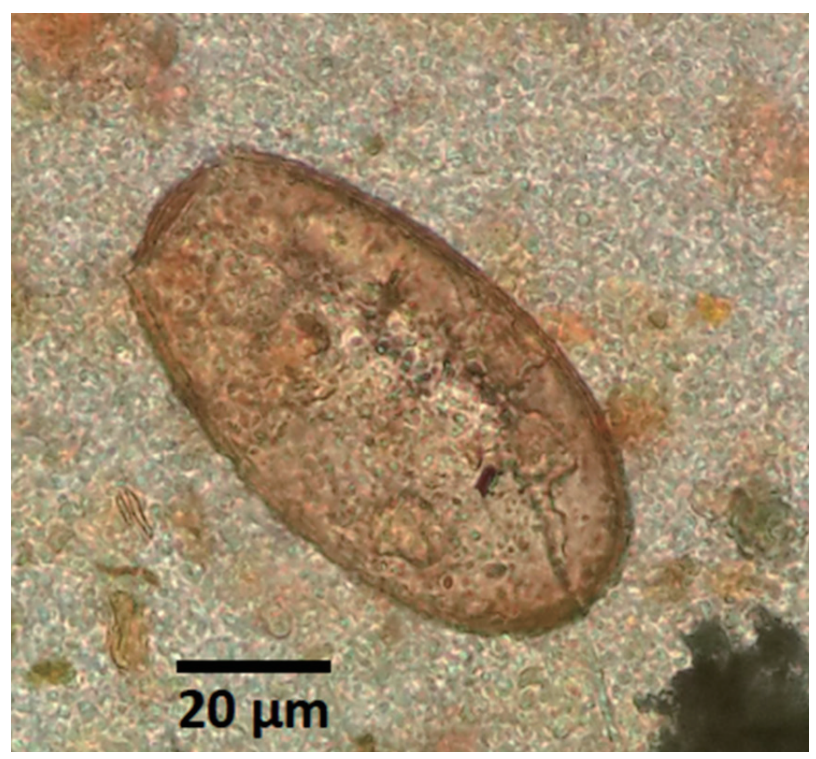

Fig. 1. A Paragonimus spp. egg found in fecal sample of a patient in Ban Mae Lah, Tak province. ed, the patient had received medication and had reduced the amount of cigarette smoking, and, accordingly, her symptoms were improved. Thereafter, the chronic cough of the patient disappeared. The patient reported the habitual consumption of semi-cooked roasted waterfall crabs, in a local dish called "poo ping", during her employment in the fields several years ago. The results of her physical examination and chest X-ray were normal, and her complete blood examination results were within the normal range.

To detect metacercariae in the intermediate crab hosts in the study area, we collected waterfall crabs, Larnaudia larnaudii, from the rocky canal with a help of local villagers. At the rocky canal, rocks were turned over and crabs were caught by hand and put into a container and carried back to the local Health Promoting Hospital for examination. The carapaces of crabs were removed, and the gills, heart, viscera, and muscles were examined separately by compression between 2 large glass plates under a stereomicroscope [15], However, Paragonimus spp. metacercariae were not found in the crabs examined in this study.

\section{Laboratory findings}

The examination of the patient's sputum was negative for Paragonimus spp. eggs. Chest X-ray was performed, but no obvious imaging abnormalities were recognized in the patient's chest X-ray images. Copro-DNA was extracted from the patient's fecal sample. Polymerase chain reaction (PCR) primers were designed from cox-1 sequence of $P$. heterotremus, in the National Center for Biotechnology Information (NCBI) database accession no. NC039430. The PCR primers used were COX1-F (5'-ACATATCTGCATGACCTTGACTAAT-3') and COX1-R (5'-CCAAGAAAAAACCTTAATCCCTGTG- ${ }^{\prime}$ ). The PCR amplicon was approximately 200-bp long. The PCR reaction mixture (final volume $50 \mu \mathrm{l}$ ) contained $1 \times \mathrm{TopTaq}^{\mathrm{TM}}$ Master Mix (Qiagen, Hilden, Germany), 20 pmol of each primer, and $1 \mu \mathrm{l}$ of the copro-DNA template at a concentration of $100 \mathrm{ng} / \mathrm{\mu l}$. The PCR master mix kit was adjusted to the final volume by adding sterile $\mathrm{ddH}_{2} \mathrm{O}$. PCR was performed on a $1000^{\text {TM }}$ Thermal Cycler (Bio-Rad, Hercules, California, USA) as follows: initial denaturation at $95^{\circ} \mathrm{C}$ for $3 \mathrm{~min}$; followed by 34 cycles of $95^{\circ} \mathrm{C}$ for $30 \mathrm{sec}, 53^{\circ} \mathrm{C}$ for $30 \mathrm{sec}$, and $72^{\circ} \mathrm{C}$ for $1 \mathrm{~min}$; and a final step of $72^{\circ} \mathrm{C}$ for $5 \mathrm{~min}$. A single amplicon of the size expected for Paragonimus heterotremus ( $\approx 200$ bp) was observed (Fig. 2). The PCR product was purified and submitted to AITbiotech Pte Ltd., Singapore, for se- 


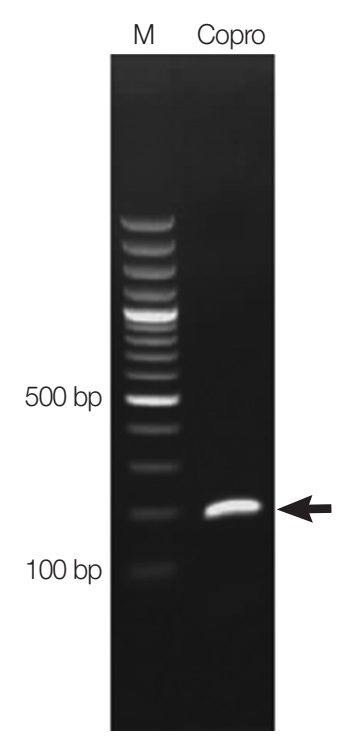

Fig. 2. A PCR product (arrow) amplified on copro-DNA of the patient.

Lane $\mathrm{M}=$ Molecular marker. Lane Copro=Amplicon of Paragonimus eggs in a fecal sample.

quencing. After blast search against NCBI database, the cox 1 sequence of Paragonimus eggs from the feces was completely (100\%) identical to the DNA sequence of P. heterotremus species. The result of DNA sequencing was deposited in the NCBI database accession no. MH536114.

A standard treatment regimen of praziquantel at $40 \mathrm{mg} / \mathrm{kg}$, single dose, was administered to the patient infected with $P$. heterotremus. The participants who were infected with other helminths were treated with albendazole (200 mg; 2 tablets) for ascariasis and hookworm; mebendazole (100 mg) twice daily for 3 days for trichuriasis; albendazole (200 mg; 2 tablets and dose repeated within 2 weeks) for enterobiasis; albendazole ( $200 \mathrm{mg}$; 2 tablets twice daily for 5 days) for strongyloidiasis; niclosamide (500 mg; 4 tablets) for taeniasis. Pathogenic protozoan infections were treated with metronidazole (200 $\mathrm{mg}$ ). The health education program was conducted during our mobile clinic service to the villagers in the community at the Chula-Thammasat school using posters and demonstration of preserved specimens of helminths, such as soil-transmitted helminths, Taenia spp., Paragonimus spp. etc. The school children and the Karen community people were educated regarding infection prevention. Because paragonimiasis was identified in the region, the information was reported to the medical staffs in the community hospital. In addition, discussions with the medical staffs were held for the promotion of further awareness of this parasite in this region.

\section{DISCUSSION}

The Northern Thailand has been known as an endemic area of paragonimiasis [5]. However, cases of human paragonimiasis have never been reported nor has the survey for intermediate hosts ever been conducted in Tak Province. To the best of our knowledge, this is the first case of human paragonimiasis in Tak Province. The patient diagnosed in this study was a Karen ethnicity. In 1991, Ekarohit et al. [9] reported that paragonimiasis patients in Mae Hong Son Province were mostly ThaiKaren villagers who habitually consume raw freshwater crabs and prawns. Although typical clinical symptoms of paragonimiasis are chronic cough and bloody sputum similar to those of human pulmonary tuberculosis, the present patient exhibited no evident symptoms. Approximately $20 \%$ of paragonimiasis patients are reported to be asymptomatic [16]. In the present study, despite detection of Paragonimus sp. eggs in the patient's fecal sample, abnormal lesions were not detected in the chest X-ray images of the patient. Such inconsistency between fecal egg detection and chest X-ray findings has been reported repeatedly [17]. Although computed tomography imaging can improve diagnostic sensitivity [18], its accessibility is problematic for individuals in remote areas and those living in poor economic conditions. Because immunoserological diagnosis has high sensitivity and specificity [19], the use of simple immunodiagnostic methods such as dot blot ELISA [20] or immunochromatography test kits [21] is recommended in the endemic regions. In the present case, unfortunately our mobile clinic did not carry such an immunodiagnostic kit for paragonimiasis. Nor were we allowed to bring back serum samples to our own laboratory. We know that there is a chance to find undigested eggs in the patient's stool which was accidentally ingested from unidentified environmental sources contaminated with Paragonimus sp. eggs. However, this possibility is rather unlikely because if the environment of our study area was contaminated with Paragonimus eggs, at least some more fecal egg positive cases should be found among over 300 fecal samples of the residents living together with the similar lifestyle in the small place. Paragonimiasis remains a prevalent health problem in certain rural areas in northern Thailand. In cases of asymptomatic patients, a detailed interview regarding dietary habits is vital. Additionally, any indication of a history of chronic cough enables the diagnosis of the suspected cases of infection. In certain cases like a present patient, who had experienced chronic cough a long time ago, had a smoking 
habit, and was screened negative for tuberculosis, achieving a definitive diagnosis is challenging. We reiterate that the specific clue for this case is the history of consuming raw or semicooked waterfall crabs. Egg detection in stool and sputum provides a definite diagnosis, but the sensitivity is rather poor. Immunodiagnosis for paragonimiasis can be performed by several laboratories in Thailand, and this test will aid in obtaining strong suggestive evidence of this disease. A dietary history is critically important to make a decision for further specific investigations to reach definite diagnosis.

\section{ACKNOWLEDGMENTS}

We would like to thank the Hospital for Tropical Diseases, Faculty of Tropical Medicine, Mahidol University for financial support during mobile medical care services in the rural areas. The extend our most heartfelt thanks to the health officers and villagers in Ban Mae Lah, the Director of Tha Song Yang District Hospital, Tha Song Yang District, Tak Province, Thailand for their kind support during field work. Our gratitude also goes to Mr. Paul R Adams and Glad Rotaru, Office of Research Services, Faculty of Tropical Medicine, Mahidol University, for English editing.

\section{CONFLICT OF INTEREST}

The authors declare that, we have no conflict of interest related to this work.

\section{REFERENCES}

1. Miyazaki I. An Illustrated Book of Helminthic Zoonoses. 1st ed. Tokyo, Japan. International Medical Foundation of Japan. 1991.

2. Nawa Y, Thaenkham U, Doanh PN, Blair D. Paragonimus westermani and Paragonimus species. In Motarjemi Y ed, Encyclopedia of Food Safety, Volume 2: Hazards and Diseases. 1st ed. Amsterdam, Netherlands. Elsevier. 2014, pp 179-188.

3. Prommas C. Paragonimiasis, opisthorchiasis and Madura foot. J Med Assoc Thailand 1928; 11: 67.

4. Upatham ES, Viyanant V, Kurathong S, Vichasri S, Brockelman WY, Ardsuengonen P. Paragonimus heterotremus infection in a community in Saraburi province, central Thailand. J Sci Soc Thailand 1995; 21: 1-9.

5. Waikagul J, Yoonuan T. Paragonimus and paragonimiasis in Thailand. In Arizono Y, Chai JY, Nawa Y, Takahashi Y eds, Asian Parasitology Monograph Series, Vol. 1, Foodborne helminthiasis in Asia. Chiba, Japan. The Federation of Asian Parasitologists. 2005, pp 139-148.
6. Bunnag D, Harinasuta T, Viravan C, Garcia DP. Paragonimiasis: endemic foci along the riparian areas of Mekong River. Southeast Asian J Trop Med Public Health 1981; 12: 127-128.

7. Ratdilokpanich K. Pulmonary paragonimiasis: a case report. Chiang Mai Med Bull 1980; 19: 147-151.

8. Sutthipunthu P, Songthanask T, Khamboonruang C, Silprasert W, Menakanit W. Paragonimiasis: a case report from Chiang Rai province, Northern Thailand. J Med Assoc Thai 1978; 61: 427-433.

9. Ekarohit D, Chesdapan C, Thitasut P, Sukonthasan K, Choochote W. Paragonimiasis in Mae Hong Son Province northern Thailand: case report. Southeast Asian J Trop Med Public Health 1991; 22: 340-341.

10. Pannarunothai S, Sukmuang U, Tiloklert M. Paragonimiasis at Nernmaprang district, Phitsanulok province, Thailand. Region Six Med J 1988; 2: 1-8.

11. Waree P, Polseela P, Pannarunothai S, Pipitgool V. The present situation of paragonimiasis in endemic area in Phitsanulok Province. Southeast Asian J Trop Med Public Health 2001; 32 (suppl): 51-54.

12. Thamprasert K. Subcutaneous abscess of neck, a granulomatous reaction to eggs of Paragonimus: a case report from northern Thailand. Southeast Asian J Trop Med Public Health 1993; 24: 609-611.

13. Cheunsuchon B, Mahakittikun V, Junnoo V. Paragonimiasis: a case report from Kanchanaburi Province, Thailand. Siriraj Hosp Gaz 1998; 50: 115-118.

14. Watthanakulpanich D, Waikagul J, Dekumyoy P, Muangkham P, Praevanit R, Mongkhonmu S. Paragonimiasis in Nan Province, northern Thailand. Southeast Asian J Trop Med Public Health 2005; 36: 853-857.

15. Yoonuan T, Vanvanitchai Y, Dekumyoy P, Komalamisara C, Kojima S, Waikagul J. Paragonimiasis prevalences in Saraburi province, Thailand, measured 20 years apart. Southeast Asian J Trop Med Public Health 2008; 39: 593-600.

16. Rosen MJ. Chronic cough due to tuberculosis and other infections: ACCP evidence-based clinical practice guidelines. Chest. 2006; 129 (suppl): 197-201.

17. Yang SP, Cheng CS, Ghen KM. Chest X-ray findings and some clinical aspects in pulmonary paragonimiasis. Dis Chest 1955; 27: 88-95.

18. Kim TS, Han J, Shim SS, Jeon K, Koh WJ, Lee I, Kee KS, Kwon OJ. Pleuropulmonary paragonimiasis: CT findings in 31 patients. AJR Am J Roentgenol 2005; 185: 616-621.

19. Narain K, Devi KR, Mahanta J. Development of enzyme - linked immunosorbent assay for serodiagnosis of human paragonimiasis. Indian J Med Res 2005; 121: 739-746.

20. Eamsobhana P, Yoolek A, Punthuprapasa P, Suvouttho S. A dotblot ELISA comparable to immunoblot for the specific diagnosis of human parastrongyliasis. J Helminthol 2004; 78: 287-291.

21. Intapan PM, Rodpai R, Sanpool O, Thanchomnang T, Sadaow L, Phosuk I, Maleewong W. Development and evaluation of a rapid diagnostic immunochromatographic device to detect antibodies in sera from intestinal capillariasis cases. Parasitol Res 2017; 116: 2443-2447. 
Supplementary Table S1. Intestinal parasitic infections by microscopic stool examination in the villagers in Tak Province

\begin{tabular}{lc}
\hline Parasites detected & No. of positive $(n=343)$ \\
\hline Helminthic infections & \\
Hookworm & $46(13.4 \%)$ \\
Ascaris lumbricoides & $39(11.4 \%)$ \\
Trichuris trichiura & $26(7.6 \%)$ \\
Minute intestinal flukes & $23(6.7 \%)$ \\
Taenia spp. & $6(1.8 \%)$ \\
Strongyloides stercoralis & $4(1.1 \%)$ \\
Enterobius vermicularis & $2(0.6 \%)$ \\
Paragonimus spp. & $1(0.3 \%)$ \\
Protozoa infections & \\
Endolimax nana & $42(12.2 \%)$ \\
Entamoeba coli & $41(12.0 \%)$ \\
Blastocystis hominis & $23(6.7 \%)$ \\
Entamoeba histolytica/dispar & $20(5.8 \%)$ \\
Giardia intestinalis & $15(4.4 \%)$ \\
Sarcocystis spp. & $2(0.6 \%)$ \\
lodamoeba buetschlii & $1(0.3 \%)$ \\
\hline
\end{tabular}

